\title{
Los Cuícatl de Acomiztli Netzahualcóyotl: entre el ritual y la estética del pueblo Nahual $^{*}$
}

Fecha de recepción: 02 de octubre de 2014

Fecha de aprobación: 25 de enero de 2016

\section{Resumen}

Este artículo muestra el aspecto literario de una de las culturas más desarrolladas del México antiguo: el pueblo azteca - náhuatl. Para este caso, se consideran los Cuícatl de Acomiztli (1402-1469). Su objetivo es develar los temas que sustentan la lírica de este príncipe de la cultura azteca - náhuatl. Para ello, se ha considerado una interpretación de los escritos desde la antropología literaria, que entiende el texto como fragmento de una cultura, por lo que el centro del análisis lo constituye el sujeto creador y su interacción con el entorno. De esa forma, se parte de conceptos, tales como: cultura náhuatl, cuícatl y visión de mundo religiosa, entre otros. Con ello, se busca exteriorizar, tanto el mensaje de libertad y esperanza que plasmó el cuicapicqui (forjador de cantos) prehispánico en sus Cuícatl, como la contribución del pueblo azteca náhuatl a las letras latinoamericanas.

Palabras clave: cultura náhuatl, cuícatl, evasión, visión de mundo religiosa, visión fatalista, raíz mítica indígena.

Citar: Ortiz Caraballo, C.D. (julio-diciembre de 2016). Los Cuícatl de Acomiztli Netzahualcóyotl: entre el ritual y la estética del pueblo Nahual. La Palabra, (29), 45-63. doi: http://dx.doi.org/10.19053/01218530.n29.2016.5700

\section{Carlos Daniel} Ortiz Caraballo

Docente de literatura latinoamericana, Universidad Autónoma de Colombia.

cortiz.caraballo@fuac.edu.co

* Este artículo es resultado de la investigación realizada desde la Facultad de Ciencias Humanas de la Universidad Autónoma de Colombia, específicamente del programa de Estudios Literarios, que desde el curso de Literatura Latinoamericana I, indaga en la raíz mítica latinoamericana, es decir, rastrea la presencia y recurrencias del legado literario prehispánico en la literatura contemporánea de nuestra región. Un primer momento de esta investigación fue socializada en el VI Coloquio Internacional Literatura Hispanoamericana y sus Valores (2010) organizado por la Universidad de la Sabana, en la Academia Colombiana de la Lengua, en la ciudad de Bogotá. 


\section{la palabra}

\section{Acomiztli Netzahualcóyotl's Cuícatl: between Nahuatl Ritual and Aesthetics}

\section{Abstract}

This article delves into the literary tradition of one of the most established cultures of ancient Mexico: the Aztec Náhuatl culture. In this case, the Cuícatl [songs] of the Aztec Nahuatl prince Acomiztli (1402$1469)$ and their main lyric topics are discussed in this article. These writings are interpreted from the point of view of literary anthropology, which understands the text as a fragment of a culture; where the center of the analysis involves the creator-subject and his interaction with the environment. Therefore, we begin with concepts such as Náhuatl culture, cuicatl and religious world view, among others. This study seeks to externalize both the message of freedom and hope delivered by the prehispanic cuicapicqui [songwriter] in his Cuicatl, and the contribution of Aztec Náhuatl culture to Latin American literature.

Keywords: Náhuatl culture, Cuicatl, evasion, religious world view, fatalism, indigenous mythical roots.

\section{Les Cuicatl d'Acomiztli Netzahualcóyotl: entre rituel et esthétique du peuple Nahual}

\section{Résumé}

Cet article analyse la littéraire d'une des cultures les plus développés du Mexique ancien: le peuple aztèque-nahuatl. Nous considérons, dans ce cas précis, les sujets lyriques des Cuicatl d'Acomiztli (14021469), prince de la culture aztèque-nahuatl. Nous proposons une étude d'anthropologie littéraire qui comprend le texte comme fragment d'une culture. Notre analyse est ainsi centrée sur le sujet créateur et l'interaction avec son entourage. Nous partons de concepts comme: Culture nahuatl, cuicatl, vision $d u$ monde religieuse. Nous voulons mettre en évidence le message de liberté et d'espoir du Cuicapiqui (inventeur de chants) préhispanique dans ses cuicatl, et la contribution du peuple aztèque nahuatl à la littérature latino-américaine.

Mots-clés : culture nahuatl, Cuicatl, évasion, vision du monde religieuse, vision fataliste, racine mythique indigène. 
"La poesía es un don divino que nos es prestado para aliviar nuestro paso por el mundo" Acomiztli Nezahualcóyol.

\section{Introducción}

La producción literaria de una comunidad es el retrato cultural más cercano que se puede trazar de ella. Un perfil en el que se logra rastrear los valores sociales e intereses particulares de aquellos que la constituyen, especialmente, el pathos de un artista lírico. Este es el caso de Acomiztli Netzahualcóyotl (1402-1469), cuyos cuicatl (cantos) refractan el pensamiento mítico de la cultura náhuatl, su pueblo.

La cultura náhuatl asciende de la familia lingüística yuto-azte$\mathrm{ca}^{1}$, cuyo territorio se extendía por América del norte, México y una gran zona de América central. Uno de sus asentamientos más importante está ubicado al lado del lago de Texcoco, en la ciudad de Tenochtitlan. Su presencia en la región central de México puede documentarse, por lo menos, desde la época de los toltecas hacia los siglos $\mathrm{X}$ y XI de nuestra era. Por la bastedad del territorio ocupado, esta cultura desarrolló diferentes dialectos, que en principio fueron expresados mediante formas simbólicas o escritura cuneiforme, que posteriormente derivó en una escritura jeroglífica. No obstante, la dificultad para unificar los distintos dialectos en un sistema de escritura único, llevó a que solo unos pocos dominaran el sistema simbólico escrito.

Sin embargo, debe tenerse en cuenta que este sistema simbólico no siempre se corresponde con los hechos consignados, debía tener un especialista que los hiciera inteligible a sus lectores o escucha, pues la escritura hacía parte de un ritual sagrado. En palabras de Todorov (2008),

Los dibujos estilizados, los pictogramas que usaban los aztecas no son un grado inferior de escritura: son una notación de la experiencia, no del lenguaje. [...] Los dibujos de los códices solo conservan los principales puntos de la historia, que, en esta forma, son ininteligibles; los vuelve comprensibles el discurso ritual que los acompaña: nos percatamos claramente de ello hoy en día puesto que algunos dibujos siguen siendo opacos para nosotros, en ausencia de todo comentario antiguo (p. 88).

Pese a esa situación, son muchos los documentos en lengua náhuatl (literarios y no literarios) que se conservan en la actualidad y han sido traducidos a varios idiomas. Dichos textos, no solo constatan el desarrollo artístico de esta cultura, a partir de géneros canónicos como: la lírica, la épica y el drama, sino también en otras áreas del saber, como: las matemáticas, la economía, la agricultura y la religión. Por supuesto, particularizados desde la visión mítica, propia de los pueblos mesoamericanos. Otro de los embates a los que fueron sometidos estos documentos fue el proceso de conquista occidental. Si bien algunos sobrevivieron a la quema, al paso del tiempo y a las

\footnotetext{
La familia lingüística yuto-azteca se extiende desde el Lago Salado de Utah hasta el mar de Nicaragua: los de lengua náhual quedaron establecidos en las regiones occidentales del actual territorio de México, sobre todo a lo largo de la costa pacífica, desde los estados de Jalisco hasta Guerrero. [...] Los primeros de estos, los llamados toltecas, penetraron por la región de Tula (Hidalgo) hacia el lago de Texcoco entre los siglos VII y VIII, señoreando al poco tiempo ya civilizados, sobre los restos decadentes de la alta cultura que había brillado aproximadamente hasta el siglo $\mathrm{V}$ de la ciudad de Teotichuacán (noreste del lago), de cuyo antiguo esplendor era testimonio la pirámide del sol. Sucesivas oleadas nahuas seguirán llegando al valle central ya toltetizados, siendo la de los mexicas la última en establecerse antes de Cortés (Osuna Ruiz, 1968, pp. 40-41).
} 
traducciones, con o sin fines evangelizadores, fueron más los destruidos y extraviados. Actualmente, hay un renacer de lo que se conoce como la Nueva Palabra $^{2}$, que se manifiesta en el rescate de la literatura indígena de México.

\section{Ethos de la cultura náhuatl}

La cotidianidad de este pueblo estaba determinada por la duali$\mathrm{dad}^{3}$, la cual se hace manifiesta desde los asuntos más sencillos de la vida, como las labores domésticas, hasta los más relevantes como la religión y el arte. Por ejemplo, un primer aspecto de esa dualidad está relacionado con el modo en que concebían el mundo. El pensamiento de la cultura náhuatl tiene un carácter absolutamente mítico y humanista que deviene del modo en que pensaban a su Dios. Es así que Tamagastad, dios náhuatl, está formado por la dualidad Masculino-Femenino, en la que Quetzalcóatl es el varón, y $C i$ paltonal, la hembra. La unión de esta pareja es complementaria, y conforman un solo ser del que devienen todas las cosas creadas (Cardenal, 1967). Tamagastad es luz y sombra, es sagrado y humano, es muerte y vida, tristeza y alegría.

Además del carácter dual, los dioses, la tierra, la existencia misma de los seres que la habitan, se encuentran determinados por un carácter sagrado, cuya esencia gravita en torno al tonalli (destino). Cada uno de los miembros de esta comunidad acepta el tiempo que le fue prescrito, al igual que el lugar que se le designó. El pueblo náhuatl, más que ningún otro, sabía que,

todo lo que existe tiene como ingrediente esencial un tonalli, "un destino". Este puede ser bueno o malo. Dioses, hombres, animales, plantas y cuanto se mira en la tierra o se sabe que existe en $\mathrm{To}^{-}$ pan, "sobre nosotros" o en Mictlan, "en la región de los muertos", solo pueden revelarnos algo de su secreto, si descubrimos su tonalli, destino. Por eso, pobres y ricos, niños $\mathrm{y}$ ancianos, todos han de consultar a los tonal-poukque, "los que conocen las cuentas de los destinos", los cómputos de las unidades de tiempo, cada una de ellas portadora de un destino. Lo calendárico es saber matemático pero también es revelación de lo oculto, magia, salvación, necesidad inescapable, norma que todo lo rige. Lo social, económico, político, religioso, individual - del nacimiento a la muerte- se cumple y se comprende en función de sus destinos, los tonalli. Estos tienen una cuenta, la del tonal-pokualli, tal como se muestra en los tonal-ámatl, los "libros de los destinos" (León Porti1la, 1983, p. 17).

La esencia del tonalli la constituye el calendario ${ }^{4}$, que en los miembros de la cultura náhuatl se manifiesta a través de ciclos, que son enumerados y recordados. De ahí que, las celebra-

2 La Nueva Palabra o el rescate de las letras del México prehispánico, tiene dentro de sus investigadores a antropólogos, historiadores, sociólogos y literatos. Entre los más reconocidos se encuentra Miguel León-Portilla, Ángel María Garibay K., Ernesto Cardenal y Birgitta Leander, entre otros.

3 Según León Portilla (1983), «Todo cuanto existe es dual en sí mismo. Así es la suprema realidad divina, Ometéotl, "el Dios dual", y así son sus hijos, los dioses de múltiples rostros cuyo ser también se desdobla y a veces se apropia de atributos ajenos, en la sucesión de las medidas y cargas de tiempo, que marcan teofanías, creaciones, enfrentamientos y destrucciones. Tezcatlipoca "el espejo que ahuma" y Tezcatlanextía, "el espejo que hace brillar a las cosas", desdoblan luego su ser y dan lugar a los cuatro Tezcatlipocas, rojo, negro, blanco y azul. Y juntamente, el Tezcatlipoca primordial, el que se nombró Tetzáhuitl, "Portento", adorado ya por los mexicas en su patria original de Aztlan-Chicomóztoc, habría de confundir sus atributos con los del ser de quien había sido tal vez su sacerdote, para resurgir como el dios tutelar de los mexicas, con el nombre y la figura de Huitzilopochtli. Y este -nueva forma de dualidad- al ser adorado en el Templo Mayor de Tenochtitlán, tendría su adoratorio junto con el de Tláloc, la deidad omnipresente y tan requerida en Mesoamérica, el señor de la lluvia, implorado en las fiestas a lo largo del calendario» (p.16).

4 Según Todorov (2005), "Los aztecas cuentan con un calendario religioso, compuesto de trece meses de veinte días; cada uno de estos días tiene su propio carácter, fausto o infausto que se transmite a los actos realizados en ese día, y aún más a las personas en él nacidas. Saber el día del nacimiento de alguien es conocer su destino; por ello es que, apenas nace un niño se acude al intérprete profesional, que es al mismo tiempo el sacerdote de la comunidad (cf.fig.6)" (p. 70). 
ciones en torno a la creación, la existencia, la muerte, los dioses, entre otros elementos de su entorno, se hagan a manera de invocación oral o cántico ritual, pues era el mejor modo de recordar a los dioses. Por ende, el tonalli y el cuicatl determinan la segunda dualidad de esta cultura, pues eran la base de estos rituales de rememoración y enumeración de los ciclos, la palabra que les daba sentido y conciencia a los miembros de esta cultura.

El tercer aspecto en que se visibiliza la dualidad del mundo náhuatl es en la organización social del pueblo. Dos castas soportan el orden de esta civilización: los macehualtin (merecidos) y los pillotl (de linaje). Aunque, en principio, todos los miembros de esta comunidad ostentaban una misma esencia, es decir, la de ser macehualtin, había diferencias al interior de esta clase. Por ejemplo, el nombre de merecidos se utilizó para designar a toda persona del pueblo que le debía servir al Dios. En ese sentido, todo ser humano está obligado a cumplir esta función. No obstante, la forma más común en que fue empleado este apelativo, fue para designar a todas las personas del pueblo que no tenían un destino divino $\mathrm{o}$ noble. En palabras de León Portilla (1983),

Los macehualtin, sumisos, poseedores tan solo de lo indispensable para subsistir, viven acostumbrados a estar al amparo de sus señores a quienes se dirigen siempre en voz baja y empleando las formas reverenciales tan frecuentes en su lenguaje. Los pipiltin, dueños de elocuente expresión, maestros de la palabra con flores $y$ cantos, rico conjunto de símbolos, dicen lo que es recto y convincente, lo que ayuda a dar plenitud y contento a rostros y corazones o aquello que, por el contrario, puede trastornar a la gente. Los macehualtin cumplen con su oficio, aman la perfección del detalle. Conocen su propia condición, expuesta a sufrimientos, hambrunas, enfermedades y muerte. No olvidan que para morir han nacido y que solo por breve tiempo se vive en la tierra... Todo es como salir a tomar el sol, dos o tres días, para marcharse luego a la región del misterio. Saben, en resumen, que a otros compete hablar de los dioses, sacar las fiestas y señalar el camino que hay que seguir en la tierra (p. 19).

El tonalli de todo 'merecido' era agradecer con su propia vida a los dioses que hicieron posible la creación en la tierra; sacrificio que se realizaba en el surgimiento del quinto sol, en la ciudad de Teotihuacán. Los de linaje, por su parte, tenían ciertos privilegios; pues, a esta casta pertenecieron los príncipes, gobernantes, sabios, sacerdotes. Ellos pagaban sus sacrificios con cuícatl, mas no con sangre. Solo a las personas de linaje les era permitido componer, cantar y danzar, dado que eran considerados los descendientes y servidores de Quetzalcóatl. Los merecidos, por el contrario, únicamente podían deleitarse escuchándolos.

Es gracias a la organización social en castas que la cultura náhuatl desarrolla una conciencia social para asumir su tonalli y las adversidades de la vida con normalidad 5 . Para este pueblo, la vida y la muerte no se oponen de modo excluyente, son medios distintos de habitar los lugares. Por ello, a la muerte se le venera y respeta, mas no se le teme. En ciertos momentos, la muerte se hace presente en el mundo de los vivos, manifestándose mediante la tristeza. De ahí justamente que, los

\footnotetext{
Todorov (2005) explica que, "El mundo se plantea de entrada como algo sobredeterminado; los hombres responden a esta situación reglamentando minuciosamente su vida social. Todo es previsible, y por tanto todo está previsto, y la palabra clave de la sociedad mesoamericana es: orden" (p. 72).
} 
miembros de esta comunidad la acepten con cierta naturalidad. Ejemplo de ello son los Cuicatl de Netzahualcóyotl, que presentan a la muerte como el mayor poder que los dioses ejercen sobre el tonalli de los seres humanos; es decir, sobre la esencia mortal o finita de sí mismo. Es por ello que, se canta y se agasaja a la muerte, para contrarrestar la sensación de tristeza que contagia en los cantores, cuando adquieren conciencia de la falta de potestad sobre la existencia.

\section{La literatura náhual}

La literatura náhuatl refracta esa forma dual y cíclica de ese pensamiento. En esencia, esta era de carácter oral, y su desarrollo fue semejante al de otras culturas antiguas. En otras palabras, primero surgió como una práctica de motivación sonora para acompañar las labores de la tierra, poco a poco se va integrando a la cotidianidad de otros quehaceres domésticos, hasta que finalmente, es vinculada a formas más elaboradas de expresiones emotivas como el canto y el baile, acompañados de instrumentos musicales. En palabras de Leander (2005),

Poco a poco, la literatura se fue separando del mundo del trabajo, se fue alejando de los campos y fue ocupando un espacio en plazas y otros lugares públicos. En estos nuevos espacios, los espectáculos se ganaban un sitio propio sobre todo relacionado con ceremonias religiosas de varios tipos. Se dice que en tiempos del Imperio Azteca, un siglo antes de la conquista española en 1519 , este tipo de ceremonias eran tan frecuentes que ocupaba más de la mitad de los 365 días del año. No es sorpresa, por tanto, que la creación poética que en la lengua náhuatl, la lengua de los aztecas y sus predecesores, los toltecas, se denominaba in xochitl in cuitatl (flor $\mathrm{y}$ canción) se convirtiera en una actividad en extremo importante en dicha sociedad. En realidad, la poesía llegó a ocupar un lugar tan importante en el mundo náhuatl que los intelectuales y sabios más sofisticados del período celebraban reuniones o tertulias literarias en las que debatían si la poesía y la creación artística en general no sería azo tle nelli in tlaticpac: quizás la única cosa verdadera en el mundo (pp. 8-9).

La anterior cita permite entender a la literatura como una actividad esencialmente sagrada, más que intelectual; una manera otra de encontrarse con la esencia divina. Muchos críticos prehispanistas se han atrevido a asegurar que parte de la teología y la filosofía náhuatl surge a partir de la literatura. Por consiguiente, a los sujetos de la cultura que se dedicaban a esta actividad cultural se les consagraban como verdaderos sabios. La literatura no solo exigía un asunto de espiritualidad, sino también de inteligencia. Muchos de sus integrantes, que se educaron en la creación de cuícatl, encontraron un modo de expresar sus emociones vinculadas a la espiritualidad de su cultura.

La literatura hacía de estos sujetos mejores seres humanos. Así lo demuestran los vocablos creados para designarla. Por ejemplo, tecpillatolli que significa "habla o razonamiento cortés y elegante" o también, "hablar otro lenguaje", por ser un obsequio divino. Es así como la entiende Ernesto Cardenal:

la poesía para los nahuas era divina, venía de arriba, de Dios, o como ellos decían: "del interior del cielo". Ometéotl, el Dios dual, el principio Masculino-Femenino (Señor y Señora) había "inventado" a los hombres como el artista que inventa una pintura o un poema, y por pinturas y poemas (por la palabra de los tlamatinime) la historia de esta creación fue transmitida de generación en generación. De allí que la poesía era divina, vehículo de la divinidad, o como decían ellos: "palabra endiosada". Todo esto lo tenemos dicho en un poema en el que a Ometéotl se le da el nombre o tributo de Quetzalcóatl 
("inventor de hombres"). (Cardenal, 1967, p. 667).

En un sentido humanista, el cuícatl se constituye en una expresión de libertad creadora, en tanto que les permite a sus miembros exponer sus emociones y anteponerlas a otras prácticas cotidianas y políticas como la caza, la agricultura, la religión y la guerra. Por ejemplo, Garibay (1968) afirma que, para el pueblo náhuatl, la poesía, el baile y el canto eran un sustituto de la guerra, "pues tanto con esta, como con la poesía, se celebraba al numen solar, cuyos soldados y servidores eran los guerreros" (3 v., XI). En ese sentido, la literatura representa un modo de estar en armonía con su entorno y con el universo.

\section{El cuícatl}

Aunque el vocablo sea poco usual, el cuicatl es la expresión lírica por excelencia del pueblo náhuatl ${ }^{6}$. Igualmente, constituye una de las pocas composicio- nes literarias prehispánicas que ha perdurado. En la cultura náhuatl, el término tiene un significado dual que alude por igual a las flores o al canto, pues la flor es la palabra que se ofrece a Ometéotl (ser supremo). En pocas palabras, el cuicatl es un canto florido o "palabra endiosada".

Garibay (1971) es uno de los prehispanistas que más ha estudiado esta literatura y considera que

el término mismo con que se designa el poema en la lengua mexicana es de contenido musical: cuicatl, que es el más común vocablo, y cuya representación gráfica era la voluntad de la palabra adornada de flores, cual si dijera "palabra florecida", no significa "poema", sino "música con palabras" o sin ellas. La gran familia de vocablos que de esta palabra derivan, entrañan siempre la unión con la música (pp. 81-82).
Desde una concepción contemporánea de literatura, los cuicatl deberían ser entendidos como canción, en tanto que tales composiciones fueron hechas para ser interpretadas a ritmo de instrumentos musicales, especialmente con el tambor, lo que implica que había una relación estrecha entre la música, el canto y el baile. Además, cuentan con una métrica acentual, sujeta a reglas rítmicamente estructuradas ${ }^{7}$.

En tanto el lenguaje y los símbolos empleados, los cuícatl se caracterizan por su sencillez en la elaboración de imágenes, basadas en procedimientos estilísticos como: paralelismos ${ }^{8}$, difrasismos ${ }^{9}$, estribillos ${ }^{10}$ y palabras broches ${ }^{11}$; elementos que los acercan a otras literaturas antiguas, pues permiten emparentar un modo de configurar el pensamiento o de aprehender y entender la realidad de las civilizaciones primitivas. En consecuencia, su simbología de estas composiciones se estructura a partir de elementos propios del

6 Según Miguel León Portilla (2008), "Gracias a la arqueología, los códices indígenas y otros manuscritos sobrevivientes, se sabe que en náhuatl se escribieron textos con una rica temática: composiciones poéticas con connotaciones religiosas, líricas, guerreras y aún eróticas" (p. 15).

$7 \quad$ El cuícatl era escrito en códices, con tinta negra y roja. Para los conocedores, esta simbología del color está relacionada directamente con el sentido ritual con que los nahual asumían su destino. Pues, según lo anterior, el color negro simbolizaba la muerte; y el color rojo, la sangre, es decir, la vida. Los conocedores consideran que esta simbología también representa la dualidad masculina y femenina (León Portilla, 2008).

8 Según Garibay (1971), el paralelismo "consiste en armonizar la expresión de un mismo pensamiento en dos frases que, o repiten con diversas palabras la misma idea (sinonímico), contraponen dos pensamientos (antitético) o complementan el pensamiento, agregando una expresión variante, que no es pura repetición (sintético)" (p. 65).

9 Según Garibay (1971), el difrasismo "consiste en aparear dos metáforas, que juntas dan el simbólico medio de expresar un solo pensamiento" (p. 19), Así mismo, el prehispanista asegura que, de todos los procedimientos estilísticos, el difrasismo es el más peculiar al náhualt, pues la expresión imaginativa a base de metáforas es la esencia de su literatura.

10 Según Garibay (1971), el estribillo es la repetición de un pensamiento al final de cada una de las partes del poema. En los cuicalt náhuatl este puede ser de tres tipos: a) estribillo largo, con una frase de variación solamente, b) estrofa larga y estribillo breve, c) equilibrio entre dimensiones de la estrofa y las del estribillo.

11 Según Garibay (1971), las palabras broches "consisten en la repetición de ciertas palabras destacadas que enlazan un desarrollo lírico con otro en dos secciones, y a veces más del poema" (p. 71). 
entorno en que se desenvolvían sus compositores, como: la selva, el águila, el tigre, las plumas, el jade, el oro, el cacao, el canto y, por supuesto, las flores. Esto es prueba de que las piezas estaban motivadas por la estética del entorno cultural náhuatl.

Igualmente, estas composiciones cumplen con una estructura sencilla: un preludio, que es una invitación ${ }^{12} \mathrm{o}$ convite a participar en el diálogo de la palabra y el canto; un cuerpo en el que se condensa la idea del texto (las flores, el misterio de la vida, el destino, etcétera), y un cierre en el que se impugnan los sentimientos de tristeza y desolación, en defensa del goce. En ellas, los cuicapicqui (forjadores de cantos) son los únicos interlocutores válidos, especialmente cuando pertenecen a la clase noble, pues ellos son quienes asumen la vocería del pueblo ante los dioses, especialmente Netzahualcóyotl.

Además de canto, el nombre cuicatl también se utiliza para designar el género lírico, que tiene la siguiente clasificación: 1) teocuícatl: canto acompañado con música de corales, cuya temática estaba inspirada en honrar y venerar a los dioses. También es considerado como canto de reyes o para celebrar a los gobernantes; 2) yaocuicatl: canto de guerra, cuyo propósito era celebrar las victorias o hazañas de los guerreros y motivar a los combatientes para obtener nuevos triunfos; 3) xopancuícatl: canto para festejar el renacimiento de la primavera, mejor conocidos como canto de flores o canto de alegría; 4) icnocuícatl: canto que se ofrecía a la muerte, la tristeza y la derrota. De este también hacen parte, los cuicatl meditativos o filosóficos (León-Portilla, 1983, p. 72); 5) pucuicatl: cantos de niños; y, 6) pilcuícatl: cantos femeninos (Garibay, 1971, p. 408).

Como género literario, el cuícatl tiene también sus propias particularidades. Este no solo se canta y se baila, sino que también se representa. De ahí que sea dable afirmar que, en el cuicatl mexicano convergen los tres géneros de la literatura clásica occidental. Por su estructura emotiva, breve y versificada, se vincula con la lírica; por las temáticas que aborda (hazañas de guerreros), con la épica; y, por la danza ritual con que era ejecutado, con el drama.

En cuanto a la característica dramática, debe agregarse que, los cuícatl eran ejecutados de diferentes maneras. Entre las más destacadas se encuentran: los "diálogos", o contrapunteo entre dos cuicapicqui, y el canto del cuicapicqui. En el primer caso, se generaba una competencia en la que vencía el cantor cuyas palabras fuesen más excelsas y contundentes para alabar a los dioses o los guerreros. Sin embargo, este contrapunteo contaba con diferentes niveles, según la experticia o formación de los cantores. Por ejemplo, en la cultura náhuatl se diferencian entre el cuicamantini (el que sabe cantos o los tiene en su memoria), los cuicaito (el que dice el canto, acaso cantando la parte que era similar a un solo), el cuicaanqui (el que inventa un canto, que lo coge de la región misteriosa en que el canto vive, o sea, en la Cuicanelhuayotl, Xochitlalpan, Tocanatlaplan), y por último, el cuicapicquil ${ }^{13}(\mathrm{el}$ que pone en ejecución un canto) (Garibay, 1971, p. 407). En el segundo caso, en el cuicapicqui recaía la responsabilidad de toda la representación, pues él debía convencer y emocionar al auditorio mediante la palabra. Estas representaciones se realizaban única y exclusivamente en los cuicacalli (casa del canto) ${ }^{14}$, que por supuesto era un sitio sagrado.

Excepto en los poemas: "Poneos de pie" y "Ponte en pie, percute tu atabal".

13 Cabe aclarar que son muchos los críticos prehispánicos que coinciden en decir que el significado de cuicapiqui era el de forjadores de cuícatl. Es decir, no solo era creador, sino también cantor.

14 Igualmente, la creación del cuícatl también se producía en sitios sagrados, entre los que están: Cuicanelhuayotl (raíz de los cantos), Xochitlalpan (tierra florida), Tocanatlaplan (sitio original del hombre, la tierra de nuestro sustento) (Garibay, 1971, p. 403). 
II. El pathos de Nezahualcóyotl: de los Teocuícatl hasta los Icnocuícatl

Nezahualcóyotl es considerado uno de los cuicapicqui más reconocidos del mundo azteca, por su condición de noble ${ }^{15}$, guerrero y artista. Críticos e historiadores coinciden en afirmar que Acomiztli Nezahualcóyolt es la figura más importante del México antiguo.

Desde los últimos años del mundo indígena hasta nuestro tiempo, el rey poeta de Tetzcoco ha sido una figura legendaria, de múltiple fama. En Nezahualcóyotl se unían de manera excepcional las aptitudes a menudo irreconciliables del guerrero, el gobernante, el constructor, el sabio en las cosas divinas y el poeta, dentro de las características que estas actividades tenían en el mundo indígena. Pero, además, él fue un hombre que trascendió a su tiempo, por las indagaciones espirituales que formuló y por la organización administrativa y la estructura legal que dio a la vida de su pueblo y, singularmente, por las instituciones cultura- les que estableció, como fueron los archivos de los libros pintados, las escuelas y consejos superiores, las academias de sabios y poetas, las colecciones de flora y fauna, y aun por el cuidado de la lengua que distinguía a sus dominios. Dentro del mundo nahua del siglo anterior a la conquista, él representa una tradición moral y espiritual, la herencia tolteca de Quetzalcóatl, que intentó oponerse a la concepción místico-guerrera de los aztecas.

El largo periodo de estabilidad y prosperidad civilizada que fueron para Tetzcoco los 41 años de gobierno de Nezahualcóyotl -que habrían de continuarse con el también feliz gobierno de su hijo Nezahualpilli, que se extiende hasta 1515- hizo del señor de Tetzcoco una figura de leyenda: sabio y piadoso, guerrero y poeta, legislador y constructor. Si algo de su fama ha cruzado los siglos, en su tiempo esta debió multiplicarse y convertirlo en un paradigma de todas las virtudes. Los azares y contrastes de su vida: aquella infancia desvalida y amenazada, la audacia juvenil con que retó el peligro y fue preparando la reconquista de su reino, su visión y habilidad como gobernante, su peculiar sentido del esplendor compartido, visible en su preocupación por las obras de servicio y ornato público, y el singular equilibrio que mantuvo entre la actividad práctica y la capacidad filosófica y poética, todo parecía contribuir para hacer de él un personaje legendario, un rey "de mucha y célebre memoria”. (Martínez, 1998, p. 20).

El llamado señor de Acolhuacan nació en tiempo 1 venado del año 1 conejo, en Tetzcoco, que equivale en la cronología occidental al 28 de abril de 1402. Hijo de Ixtlilxochitl, señor de Tetzcoco, y Matlacihuatzin, hermana del señor de México. Su nombre tiene diferentes significados en náhuatl: "brazo o fuerza de león" y "coyote hambriento". Debido a su origen noble, a los seis años fue enviado a la escuela de gobernantes (Tlacateo) para iniciar su formación como futuro líder del pueblo de Tetzcoco. En este lu-

15 De entre "los de linaje", los pipiltin, proceden los sacerdotes mexicas, los que saben acerca de los dioses y dirigen los ritos y todas las ceremonias en las fiestas. También son pipiltin los supremos gobernantes, los más altos jueces, los capitanes, los maestros, los sabios, los forjadores de cantos... Los pipiltin, dueños de elocuente expresión, maestros de la palabra con flores y cantos, rico conjunto de símbolos, dicen lo que es recto y convincente, lo que ayuda a dar plenitud y contento a rostros y corazones o aquello que, por el contrario, puede trastornar a la gente. (León Portilla, 1983, p. 18). 
gar, se le instruía tanto para administrar el arte de la guerra y la composición literaria, con lo que queda demostrado, una vez más, que la literatura era considerada una tradición noble para este pueblo.

En su obra hay epítetos que no solo describen un modo de ser y de estar en la vida, sino también un encuentro con la palabra. Por ejemplo, como heredero de un reino, tuvo claro que saber gobernar no era suficiente para ser un buen líder; también se debía celebrar la vida, "ataviarse con flores" en tiempos de treguas. Cabe destacar que, bajo su gobierno edifica numerosos palacios y templos. Entre estas edificaciones, las más destacadas son la universidad, la biblioteca, los Consejos de Gobierno y los tribunales. Como guerrero, supo que el verdadero enemigo estaba dentro de sí, por todas aquellas dudas que lo llevaron a cuestionarse e interrogar al "dador de la vida".

Como poeta, enalteció la tradición lírica de su cultura. A Nezahualcóyotl se le atribuye el mayor número de composiciones; las cuales suman unas treinta y seis en total, de las doscientos de las que se tiene conocimiento (Martínez, 1972, p. 3). Fue el único que abordó, casi en su totalidad, las temáticas de la poesía náhuatl, en las que se destacan los cánticos con temáticas sacras, de apreciación de la naturaleza, la guerra, etcétera. Sin embargo, su originalidad se debe a que amplió el paradigma de la poesía del México prehispánico con meditaciones personales y la función artística $^{16}$. Asuntos como la veneración a los dioses, la aceptación del destino, la celebración de la vida, se destacan entre sus temas predilectos.

Sea cual sea el asunto tratado, la finalidad de Nezahualcóyotl con estas composiciones fue reflexionar sobre el destino, celebrar la vida e invitar al goce; características que ubican a las temáticas de sus cuícatl dentro de la tipología de los teocuicatl y los icnocuícatl, principalmente. Los siguientes títulos sirven de ejemplo: "Nos enloquece el dador de vida”, “¡Ay de mí!”, "Pongo enhiesto mi tambor", "Nos atormentamos", "Ay, solo me debo ir", "¿A dónde iremos?" y "Dolor y amistad". En todos los cuícatl mencionados prevalece la incertidumbre, con lo que demuestran el desconocimiento acerca del más allá.
Asimismo, las composiciones: "Estoy embriagado, lloro, me aflijo", "Deseo de persistencia", "Esmeraldas de oro", "Mientras que con escudos" y "Esmeraldas y turquesas" exponen la problemática del ser y la fugacidad de su destino. Del mismo modo, textos como: "Poneos de pie" y "Ponte en pie, percute tu atabal" sirven de preludio para la fiesta ritual de los diálogos de cuícatl. Igualmente, en los cuícatl: "Los cantos son nuestro atavío" se exponen el valor y sentido que esta cultura le daba a las alabanzas o palabras sagradas. Estos son un valor agregado de tranquilidad y dicha; es decir, simbolizan el consuelo que no tienen en la tierra: "Tus flores, oh Árbitro Sumo.../ Debemos dejarlas al irnos: / ¡Por eso lloro, me pongo triste!". En estas composiciones se expone la palabra como un sentimiento de fe, y al tiempo, con resignación ante la tristeza ineludible.

En esta misma línea temática están las composiciones acerca de la fe en un dios único y omnipotente, una de las grandes preocupaciones de los cantos náhuatl. Dentro de estas, se destacan composiciones como: “¿Eres tú verdadero?”, "Solamente él”, “¡Es un puro jade!”,

16 Según José Luis Martínez (1972), “la noción individual de la creación artística, índice de la madurez de una cultura, estaba justamente surgiendo en la cultura náhuatl. Además, a nivel de la estructura de estas composiciones hay una serie de referencias o atribuciones expresas en primera persona que demuestran que la poesía náhuatl que conocemos se encontraba precisamente en el período de transición de la creación anónima a la creación individual, y que Nezahualcóyotl es el primer poeta que pertenece ya plenamente a la nueva etapa. Por lo que lo que la originalidad de cada poeta, será el resultado de la proyección de sus peculiaridades espirituales y de las circunstancias de que surgen sus cantos" (p. 101). En cuanto vamos reconociéndolas, acaban por surgir el "rostro y el corazón" de cada uno de ellos (p. 103). 
"Comienzo a cantar", “Tú, ave azul", "Como una pintura nos iremos borrando".

\section{Los icnocuícatl de Acomiztli Netzahualcóyotl}

En las composiciones de Nezahualcóyotl, el lector percibe, casi que de inmediato, el modo en que este cuicapicqui coloca los sentimientos en sus palabras, el modo ritual en que las vivió. Él no solo compuso los cuicatl que hoy conocemos, sino también propone una particular manera de cantar, caracterizada por el diálogo con su pueblo, la plegaria con su dios y meditación consigo mismo. Es justo esa particularidad de sumergirse en el canto, de asumirlo como una reflexión para hallar un significado de la existencia individual y colectiva, lo que se denomina en estas composiciones evasión (Aguiar e Silva, 1972, p. 61). En términos generales, se puede afirmar que,

.. la evasión significa siempre la fuga del yo ante determinadas condiciones y circunstancias de la vida y del mundo, y, correlativamente, implica la búsqueda y la construcción de un mundo nuevo, imaginario, diverso de aquel del cual se huye, y que funciona como sedante, como compensación ideal, como objetivación de sueños y aspiraciones (Aguiar e Silva, 1972, p. 61).
Para el caso de Nezahualcóyotl, la evasión ${ }^{17}$ deviene de la reflexión sistemática sobre sus creencias, de la incomprensión de las leyes que rigen la vida. Para él, los dioses son los que decretan el destino del cosmos y sus habitantes. Su omnipotencia, arbitrariedad e incomunicabilidad lo llevan de la perturbación e inhibición al rechazo ${ }^{18}$ de dichas leyes. Solo hasta que logre la comprensión ${ }^{19}$ absoluta de las reglas que rigen el universo, dejará de meditar sobre "El Dador de la Vida" y sus motivos.

Es desde ese desasosiego que Nezahualcóyotl elabora una visión de mundo religiosa ${ }^{20}$ que toma como esencia los interrogantes sobre dios, el mundo y

17 Según Aguiar e Silva (1953), la evasión como fenómeno literario se da tanto en el escritor como en el lector. En el plano de creador literario sobresalen los siguientes motivos: a) Conflictos con la sociedad: el escritor huye de la mediocridad, la vileza y la injusticia de la sociedad que le rodea para refugiarse en la literatura. b) El escritor huye de sus problemas y sentimientos tortuosos y se refugia en el texto que crea. c) "Recusación de un universo finito, absurdo y radicalmente imperfecto. En general, esta recusación envuelve un sentido metafísico, pues implica una toma de posición ante los problemas de la existencia de Dios, de la finalidad del mundo, del significado del destino humano, etc." (p. 61). Esta última es la que caracteriza el plano de la creación en Nezahualcóyotl, por supuesto, asumiendo el término escritor en el sentido más amplio, es decir como creador.

18 Según Aguiar e Silva, la evasión del escritor puede realizarse, en el plano de la creación literaria, de seis modos distintos: 1) Se asume la literatura como religión, al punto de que el artista olvida el mundo y la vida. 2) Como fuga en el tiempo hacia épocas remotas llenas de una belleza que el presente no ofrece. 3) También como fuga en el espacio o lugares exóticos. 4) Fuga hacia la infancia para instalarse en la pureza e inocencia propia de estos años y ante todo, escapar de los problemas y desilusiones de la edad adulta. 5) La creación de personajes como procedimiento de evasión. Y 6) El ensueño, los paraísos artificiales provocados por las drogas y el alcohol, la orgía, etc., representan otros procesos de evasión con amplia proyección en la literatura. Nezahualcóyotl, como todos los poetas náhuatl, asumen la evasión artística desde la primera característica.

19 Es justo esa sensación dual de saber - desconocer y tristeza - goce lo que constituye el eje de tensión de estas composiciones.

20 Dilthey (1995) define la visión de mundo como un discernimiento de la realidad, que se construye, a partir de la experiencia de vida. Cuanto más experimenta y siente (temples vitales) el ser humano, más posibilidades tiene de alcanzar el conocimiento sobre el entorno o realidad circundante, pues su experticia o conocimiento de la vida, lo colocan en una posición privilegiada ante los demás. En otras palabras, una visión de mundo es un cúmulo de saberes construidos a modo de legado humano. Dilthey clasifica ese saber en tres tipos, estos son: visión de mundo religiosa, la visión del mundo poética y la visión del mundo metafísica. La primera puede entenderse como el saber mítico, pues está estructurada a través de la contemplación mística que se hace de la realidad; es decir, todo deviene de una fuerza superior, como lo expone Nezahualcóyotl. En cuanto la segunda, apunta a una contemplación artística de la realidad (Dilthey, 1995, p. 55). Y la última, se basa en una interpretación racional o cuestionable del entorno. 
los seres humanos; interrogantes que seguro motivaban otras batallas, otros encuentros. Es el ser humano enfrentado a sí mismo, a su destino o el que han impuesto los dioses sobre sí; la búsqueda del sentido de la vida. Veamos cómo se configura esta idea en el cuicatl "Poneos de pie":

¡Amigos míos, poneos de pie! Desamparados están los príncipes, yo soy Nezahualcóyotl, soy el cantor, soy papagayo de gran cabeza. Toma ya tus flores y tu abanico. ¡Con ellos parte a bailar!

Tú eres mi hijo, tú eres Yoyontzin. Toma ya tu cacao, la flor del cacao, ¡que sea ya bebida!

¡Hágase el baile comience el dialogar de los cantos!

no es aquí nuestra casa, no viviremos aquí, tú de igual modo tendrás que marcharte.

(Nezahualcóyotl, 1992, p. 9) ${ }^{21}$.

El tema de este cuícatl es el goce y disfrute de la vida; la invitación al baile y al diálogo de los poetas entre flores y cacao. El convite a participar de la celebración de los cánticos rituales, que trasciende hasta dejar de lado la tristeza y el desamparo que agobiaba a los príncipes como Nezahualcóyotl. Con ello se evidencia la presencia del eje de tensión de tristeza-goce, antes mencionado.

\section{Los teocuícatl o el pensamien- to mítico de Netzahualcóyotl}

Para el cantor, el alcance de sus composiciones trascendía las posibilidades de la celebración colectiva y las reflexiones íntimas, para centrarse en el fortalecimiento del vínculo que comparten los nobles con el pueblo náhuatl, y todos con las deidades. Según él, ese era el único medio que tenían los miembros de su comunidad, principalmente los de su linaje, para meditar sobre sí mismos y su entorno. Dicho de otra forma, los cantos constituían otro medio para que el cantor venerara y se comunicase, en nombre propio y del pueblo que representaba, con los dioses en una exacta comunión. Por ello, es posible visibilizar la interpretación que hace el poeta de sí mismo y de su cultura. Justamente en ese doble proceso de adoración y comunión radica la esencia de los cuicatl de Nezahualcóyotl, caracterizados por la búsqueda de respuestas para la tranquilidad de su pueblo.

De lo anterior, se explica que uno de los temas más provocadores de Nezahualcóyolt sea la soledad del ser. Este se basa en la búsqueda de la divinidad, que, por razones desconocidas, se encuentra oculta, o no ha manifestado su presencia divina, por lo que tanto él como su pueblo se sienten algo desamparados. No obstante, la derrota, representada en actitudes de congojas y lamentos, se muestra como opción. Por este motivo, Nezahualcóyotl emprende la búsqueda al encuentro de esa divinidad. Veamos las palabras de "Canto de huida":

Me he doblegado

Solo vivo con la cabeza inclinada

al lado de la gente.

Por esto me aflijo, ¡soy desdichado!, he quedado abandonado al lado de la gente en la tierra. (p. 33)

La muerte se convierte en un misterio que inspira toda esta lírica. Un misterio que solo puede ser contrarrestado por medio de las flores. De la muerte, lo único que se sabe es que nadie regresa del "lugar de los sin cuerpo". La vida es prestada, en la tierra se viene a sufrir y solo el canto y el baile se convierten en remedio para el dolor y el sufrimiento. Esta es la idea que se maneja en composiciones como: "Cual joyeles abren capullos", "Con flores negras veteadas de oro", entre otras.

$21 \quad$ Nezahualcóyotl, A. (1992). Poetas de España y América. Colección de poesía Quinto centenario. (Antología 1). Bogotá: Editorial Tiempo Presente. Todas las citas procederán de esta edición. 
El eje de tensión de estos cuícatl lo constituyen unidades dialécticas como saber-desconocer y tristeza-goce. Asimismo, persisten como eje central de las meditaciones filosóficas de la lírica de Nezahualcóyotl. De este eje de tensión deviene el carácter reflexivo que define a estas composiciones y les otorga esa particularidad de ritual catártico. Las preocupaciones por la existencia, la espera de una respuesta de ese dios que se mantiene oculto y los consejos de gozo, son la base del pensamiento de Nezahualcóyotl. $\mathrm{Su}$ esencia se vincula con el porqué de la vida, con un sujeto que se enfrenta a sí mismo, a su propio destino o al que los dioses han impuesto sobre él. No obstante, estas composiciones trascienden los sentimientos de congoja, pues el forjador de cantos toma todo ese dolor y lo convierte en un sentimiento positivo; invita a sus escuchas a la celebración de la vida, ante el dolor inexorable.

Si la lírica náhuatl se caracteriza por su sencillez; las composiciones de Nezahualcóyotl, por la expresión de emociones, mediante la elaboración de imágenes nativas contundentes; imágenes que, además de ser un modo de evasión ante el dolor de la muerte, también exponen un principio de individuación cultural, es decir, un modo de ser y conocerse a sí mismo, como a su propia cultura. En el siguiente fragmento de "Con flores negras veteadas de oro" se evidencia lo expuesto:

¿Acaso así se vive ahora

y así se vive allá en el sitio del misterio?

¿Aún allí hay placer?

$¡ A h$, solamente aquí en la tierra: con flores se da uno a conocer, con flores se manifiesta uno, oh amigo mío!

Engalánate con tus flores

flores color de luciente guacamaya,

brillantes como el sol; con flo-

res del cuervo

engalanémonos en la tierra, aquí, pero solo aquí.

Solo un breve instante sea así: por muy breve instante se tiene en préstamo

sus flores.

Ya son llevadas a su casa.

$\mathrm{y}$ al lugar de los sin cuerpo, también su casa,

y no con eso así han de perecer nuestra amargura, nuestra tristeza.

(p. 12).

El tema central de esta composición es, sin duda, el cuícatl, en la metáfora de las flores; es un homenaje que se hace al canto desde el canto. El cantor se refiere a su creación como un don divino, que lo engalana, al tiempo que lo reviste de conocimiento y espiritualidad. La percepción que este pueblo ofrece de la creación lírica, es la de un estilo de vida consagrado a la celebración y la adoración, como esencia de su modus vivendi. Es así que, los cantos son la respuesta a los interrogantes que se hace el poeta. Sin embargo, la duda persiste como un amargo sabor, ante la incertidumbre de saber si estos cantos serán suficiente para saciar todas las preguntas sobre el dios y el más allá.

Así, la poesía y los cantos son trasmutados a las flores. Cantos y flores tienen un efecto embriagador, catártico y sanador, como se expone en el siguiente fragmento:

Sobre las flores canta

el hermoso faisán,

su canto despliega

en el interior de las aguas.

A él responden

varios pájaros rojos,

el hermoso pájaro rojo,

el hermoso pájaro rojo

bellamente canta.

Libro de pinturas es tu corazón, has venido a cantar, haces resonar tus tambores, tú eres el cantor.

En el interior de la casa de la primavera, alegras a la gente.

Tú solo repartes

flores que embriagan,

flores preciosas.

Tú eres el cantor.

En el interior de la casa de la primavera,

alegras a las gentes.

("Canto de primavera", p. 15).

El cuicapicqui toma distancia del sufrimiento y la amargura que se padece en la tierra, gracias a las flores que permiten 
la construcción de la evasión como una droga, como efusión. Es con ellas que Nezahualcóyotl presenta su ofrenda a su dios. Este cuícatl se erige como un canto ritual, del que resultan las epifanías sobre el arte de la palabra.

Las flores son muy simbólicas en estas obras, en algunos casos hacen referencia a la vida, otras veces se refieren a los cantos; la última referencia es la más común. Cuando un cuicapicqui como Nezahualcóyotl ofrece flores a los dioses, no busca otra cosa que saciar el dolor y la amargura que puede significar vivir y acatar un destino cruel. Por ello, agradece de tal modo, para reconocer su propia inferioridad y el poder del dios, como queda expuesto en los siguientes fragmentos:

¡Es puro jade, un ancho plumaje tu corazón, tu palabra, ¡Tú lo ves con piedad!... ¡solo por un brevísimo instante está junto a ti y a tu lado! Preciosas cual jade brotan tus flores, oh por quien todo vive; cual perfumadas flores se perfeccionan,

cual azules guacamayas abren sus corolas...

¡solo por un brevísimo instante está junto a ti y a tu lado!

(“¡Es puro jade!”, p. 29).

Los cuicatl de Nezahualcóyotl son en esencia una plegaria, una oración de alabanza. La magia, la mística, el elogio y la adoración son frecuentes en esta lírica. Al parecer siempre se recalca la brevedad de la vida, para reconocer su poderío y su belleza, otro modo de admitir la supremacía de dios. Para él, todo parece obedecer a un acto de ley natural en el que tanto el destino, como la vida de todos los habitantes de su pueblo, están prescritos. Nada es accidental, todo cuanto existe tiene como ingrediente esencial el tonalli que está sujeto al capricho de los dioses. Aunque no siempre se acepte, no significa que se esté en contra de él. La mayoría de las veces, el cuicapicqui aprende a llevar su destino con resignación.

El tema del cuícatl ¡Es puro jade!, es la duda sobre la existencia del dador de vida.
El cuicapicqui reflexiona acerca del origen y su esencia omnipresente. Él, ante todo, no lo cuestiona ni lo juzga; acusa a quienes así lo hacen. Sabe que, aunque no esté de acuerdo con los dioses, exige respeto.

\section{El mensaje emancipador de Nezahualcóyotl}

El mensaje que elabora Nezahualcóyotl en sus composiciones está inspirado en el rito de la $\mathrm{fe}^{21}$. Es mediante lo religioso que se puede penetrar más en el pensamiento del pueblo náhuatl. El tema religioso pone de manifiesto la meditación sobre la relación del hombre con la divinidad y cómo esto es lo que tiene verdadero sentido. El tema suele figurarse como uno de los puntos principales de estas piezas, ya que remite inmediatamente a ese sentido de respeto que se mencionó en el párrafo anterior. En la composición " $i A y ~ d e$ mí!", se evidencia del siguiente modo:

¡Ay de mí

sea así!

No tengo dicha en la tierra

Aquí.

$21 \quad$ La religión como fundamento esencial de un pueblo acarrea consigo ciertos problemas que se manifiestan entre sus participantes en dudas y contradicciones, no por falta de fe, sino mas bien por no alcanzar a entender con certeza el designio de la deidad. El pueblo nahua tuvo la necesidad de una razón más allá de sí, en la que fundamentó los preceptos de su vida. Ellos se perfilaron, a partir de estas creencias extrasensoriales, de los parámetros divinos de la religión. Como lo asegura Alfonfo Caso (citado en Garibay, 1968): "La religión era el factor preponderante e intervenían como causa hasta en aquellas actividades que nos parecen a nosotros más ajenas al sentimiento religioso, como los deportes, los juegos y la guerra" (V, III: XIII). Fue mediante el mito religioso que los nahual, como todas las culturas amerindias, intentaron dar una explicación lógica a cada uno de los misterios, a todo fenómeno natural y a todos y cada uno de los que habitan en la tierra. Con lo que dejaron por sentado, que existe algo más allá, más grande de sí mismo, donde el sentido de su pertenencia con el cosmos, su esencialidad fue saciado. 
¡Ah, de igual modo nací, de igual modo fue hecho hombre!

¡Ah, solo el desamparo

he venido a conocer aquí en el mundo habitado! ¡Que haya aún trato mutuo aquí, oh amigos míos: solamente aquí en la tierra! Mañana o pasado, como lo quiera el corazón de aquel por quien todo vive, nos hemos de ir a su casa, ¡oh amigos, démonos gusto! (p. 35).

En este cuícatl se percibe la idea de vivir sometido bajo un destino inevitable. La interpretación de estas palabras se podría entender como la resignación ante un destino del que no se es dueño. El canto es la expresión de un temor y el dolor que causa lo incierto, así como la ausencia de dominio de los nobles, como Netzahualcóyotl ante el destino. Es por esa razón que, como cuicapicqui, perteneciente a una casta noble, demanda un trato mutuo. De ese modo, no le queda otra salida que, concluir con una fórmula de invitación al goce, mientras sigue esperando el llamado de los dioses. Esta fórmula se repite insistentemente en todos los poemas y permite la construcción de un estado evasivo hacia el disfrute de la vida.

La vida es efímera como todo lo que hay sobre el mundo náhuatl. Todo parece obedecer a un acto de la ley natural en el que tanto el destino como la existencia del ser de este pueblo se hallan sujetos al capricho de los dioses. Así se muestra en los siguientes fragmentos:

¿Eres tú verdadero (tienes raíz)? Solo quien todas las cosas domina,

El Dador de la Vida.

¿Es esto verdad?

¿Acaso no lo es, como dicen?

¡Que nuestros corazones

no tengan tormento!

Todo lo que es verdadero

(lo que tiene raíz)

dicen que no es verdadero

(que no tiene raíz)

El Dador de la Vida

solo se muestra arbitrario.

¡Que nuestros corazones

no tenga tormento!

Porque él es el Dador de la Vida (p. 27).

El tema de esta composición es la duda sobre la existencia de "El Dador de Vida". El Nezahualcoyotl reflexiona acerca del origen y su esencia omnipresente. Ante todo, no existe cuestionamiento o juicio; por el contrario, acusa a quienes así lo hacen, a aquellos incrédulos. En consecuencia, él construye su mensaje de fe, a partir del respeto a los dioses.

La relación del misterio llega con la muerte y es la puerta que cierra el destino, es la idea de que hay algo más allá, lo que posiblemente hace tolerable la vida en este mundo. Así se evi- dencia en "Como una pintura nos iremos borrando":

En esta forma tachas e invalidas la sociedad (de poetas), la hermandad,

la confederación de príncipes.

(Metes en tinta)

matizas de colores

a todo lo que ha de vivir en la tierra.

Luego queda rota

la orden de Águilas y Tigres:

¡Solo en tu pintura

hemos venido a vivir aquí en la tierra!

(p. 38).

En el poema anterior, se muestra la idea de la muerte como destino inexorable, hasta para los de alto linaje. Por más que se quiera entender las acciones de los dioses estelares, todas resultan como un juego de azar, arbitrarias. El dolor es por la vida, su brevedad, por lo que no se conoce. Ante la incertidumbre, surge ese miedo; miedo probablemente a extinguirse, a dejar de existir.

Nezahualcóyotl temió, dudó y no entendió a cabalidad el designio de los dioses; por ello, se resignó. Esto probablemente no lo hace diferente a ninguno de los hombres a lo largo del tiempo; sin embargo, después de encarar a sus dioses, quizás lo que más angustia le causaba era ser juzgado ante ellos. Al fin y al cabo, él era un monarca, y eso para los náhuatl significaba ser el representante de los dioses 
en la tierra, al tiempo que un dios para su pueblo. En el más allá no sería igual, simplemente uno más. Así se expone en las siguientes palabras:

Tenedlo entendido:

Tendré que dejaros, oh amigos, oh príncipes.

Nadie vale nada ante el Dador de la vida,

Él nos va quitando, él nos va arrebatando

$\mathrm{Su}$ fama y su gloria en la tierra.

Lo has oído, corazón mío,

Tú que estás sufriendo:

Atiende a nosotros, míranos bien:

Así vivimos aquí ante el dador de la vida.

No por eso mueras, antes vive siempre en la tierra.

(“Dolor y amistad", p. 41).

Estas composiciones iban acompañadas siempre de músicas y danzas. Queda por sentado que, estos textos eran utilizados como medios para mermar el sufrimiento que acarreaba la situación ante la vida, como quien dice, "se muere porque no hay alternativa, pero se vive y se goza primero". Lo importante de la fe en la lírica náhuatl es el pensamiento que Nezahualcóyolt logra elaborar, es decir, la conciencia clara de la muerte, la idea fatalista que tejieron sobre el tema. En otras palabras, el valor real de esta lírica lo constituye el modo en que no se dejaron vencer por la angustia. He ahí su rubro de arte, pues las creaciones del príncipe-poeta fueron la energía para expresarse por medio de sus cantos, la inspiración de los mismos. Según Miguel León Portilla (1982),

[...] ellos elucubraron $\mathrm{y}$ se expresaron por los caminos del canto y la palabra, a partir de su visión de un mundo de realidades opuestas pero complementarias, aceptando una dualidad trascendente, un universo cambiante, amenazado de muerte. $\mathrm{Su}$ grandeza se derivó en alto grado de esto: saber que, en su destino y en el de su universo, ingrediente inexplicable era la muerte, pero no desmayar nunca por ello, mantenerse siempre en acción, con la conciencia cierta de que, si no podían suprimir el acabamiento, en su mano está posponerlo, ensanchando así el ámbito del existir humano en la tierra, el ámbito de la historia (p. 27).

Tal apreciación es evidente, dado que la entonación de los poemas se asume en esencia ritual y así se asumen estos textos como para mermar el dolor y el vértigo inmanente hacia un destino inevitable. Es así como lo testifica Nezahualcóyotl, el cantor.

\section{Consideraciones finales}

Las composiciones de Nezahualcóyolt siempre apuntan a la mortalidad del ser, a la brevísima instancia en la tierra, a la congoja que la mortalidad suscita, pero también al goce del entorno y sus riquezas. A nivel estructural, estas composiciones se sostienen en los símbolos de la naturaleza (colorido de las flores, aves y minerales), como en las creencias de fe míticas. Es decir, son "cantos" que exaltan el valor natural del entorno espacial humano en que se desenvolvía la cultura nahua. Esta herencia mítico-simbólica es la que Fernando Cruz Kronfly (1998) ha denominado "matriz aborigen", que para este caso es denominada como raíz mítica indigena. Este concepto se trae a colación para nombrar el sustrato simbólico - literario americano, con el que se aprehende el "corpus" de los elementos propios de la cultura indígena de la región, se resuelve la pregunta ontológica sobre "el ser americano", y, por supuesto, una latente literatura propia de América. Según Fernando Cruz Kronfly, este sustrato no solo se ha perpetuado en la literatura latinoamericana, sino que también es lo que le otorga su carácter particular o identidad. Es así que,

a estas alturas, la vieja y resistente matriz mítica aborigen, a la que se había sumado la mitología africana, no solo no había logrado ser borrada ni sojuzgada a causa de la superposición histórica del barroco colonial, el romanticismo de la Independencia, el criollismo subsiguiente y el modernismo, 
sino que resultaba ahora revivida por el reconocimiento europeo a través del surrealismo, una de sus más prestigiosas vanguardias. De esta manera, el siglo XX literario en América Latina, especialmente en su vertiente «real maravillosa» o del «realismo mágico», retoma $\mathrm{y}$ reelabora aquella matriz mítica jamás desaparecida, para pasar a instalar en el centro del lenguaje y de su ficción, como una maceta de geranios. Aquella matriz mítica, en cuanto tal, no se refería por supuesto solo a los relatos fundadores y del origen, que sin embargo en algunas obras ingresaron casi intactos, como en el caso de Miguel Ángel Asturias, sino de manera aún más perturbadoras a las relaciones de causalidad entre los fenómenos. La racionalidad occidental, con su severa lógica «objetiva», jamás daría, por ejemplo, al hecho de alguien llevarse a los pies un zapato equivocado al saltar del lecho, el mismo significado y alcance que le otorga la causalidad mítica, fundadora de la mirada agorera, presa de la idea de la inexorabilidad de los presagios. Que es lo que precisamente advierte Suetonio respecto de $\mathrm{Au}-$ gusto: «Si por la mañana le ponían en el pie derecho el calzado del izquierdo lo tenía a mal presagio»». Este recurso literario, típico de nuestro García Márquez y de la corriente de lo real maravilloso, no fue sin embargo común a otras literaturas latinoamericanas que habían hecho ya la modernidad de otro modo, como en Argentina. Pero, habida cuenta de estas definitivas diferencias $\mathrm{y}$ haciendo el registro de las imprescindibles excepciones, la cuestión de la «identidad» del hombre latinoamericano se convirtió de pronto en el tema axial de las literaturas de los años sesentas, cuestión que, por supuesto, venía gravitando ya desde la iniciación del siglo, como parte de nuestro proyecto cultural y político (pp. 233-234).

Así, es posible advertir que ese pensamiento mítico, ese modo de concebir el entorno, que rompe con la lógica objetiva de occidente e impone su propia lógica centrada en la causalidad mitológica e imaginativa, que conjura poderes sobrenaturales para comunicarse con el más allá, es producto de la raíz mítica indigena que tiene su origen en las diversas literaturas de los pueblos de América, como el náhuatl.

A diferencia de los demás poetas del pueblo Azteca-Náhuatl,
Nezahualcóyotl asume la lírica como un ejercicio catártico, en el que intenta evadir su dolor mediante el gozo (la puesta en escena del canto y la danza). Valga agregar que, por el tema que presentan los códices, el príncipe-poeta puede ser considerado uno de los primeros líderes de las letras del continente, pues condujo a su pueblo a la libertad y la tranquilidad espiritual, mediante una propuesta ética-estética que invita a asumir una postura práctica ante la vida. Es así que, el pensamiento del príncipe-poeta está sustentado en dos temas principales: el primero, el sentido fatalista de la figura de un hablante poético impotente ante el designio que se ha establecido para el pueblo Azteca-Náhuatl; el segundo, el mensaje de libertad y esperanza que Netzahualcóyotl les imprime a sus escritos para contrarrestar el trágico destino que le han impuesto los dioses a su pueblo. El significado de estas composiciones radica justamente en establecer una poética de gozo y disfrute inmediato ante la fatalidad del destino, así como figura en las palabras de Nezahualcóyotl que rezan en el epígrafe de este trabajo.

Para terminar, no está de más decirle a los lectores que no están habituados a este tipo de literatura, que se van a deleitar con la lírica de esta comunidad, pues, estos cantos ofrecen además de una visión del mundo náhuatl, del fragmento de un 
alma que espera ser descubierta, un panorama del legado prehispánico literario de México y, aún más, la recurrente presencia en la literatura contemporánea de nuestra región. Existe una rica literatura en lengua náhuatl, tanto de tradición prehispánica como en el periodo colonial. La invitación, entonces, es a revi- sar esta y otras literaturas de Latinoamérica hasta completar los vacíos de la raíz mítica indígena.

\section{Referencias}

Aguiar e Silva, V.M. de (1972). Teoría de la literatura. Madrid: Gredos.

Cardenal, E. (1967). In Xóchitl in Cuícuatl. La palabra y el hombre, (44), 665-695.

Cardenal, E. (1968). Netzahualcóyotl. Anales de la Universidad de Antioquia, (171), 370.

Cruz Kronfly, F. (1998). La tierra que atardece. Ensayos sobre la modernidad y la contemporaneidad. Santafé de Bogotá: Planeta Colombia Editorial S.A.

Dilthey, W. (1995). Vida y poesía. México: Fondo de Cultura Económica.

Garibay K., Á.M. (1963). Panorama literario de los pueblos nahuas. México: Porrúa S.A.

Garibay K., Á.M. (1968). Paleografia, versión, introducción, notas y apéndices. En: Poesía náhuatl III. México: Universidad Nacional Autónoma de México.

Garibay K., Á.M. (1971). Historia de la literatura náhuatl (Vol. I). México: Editorial Porrúa.

Leander, B. (2005). La lengua náhuatl: literatura del México antiguo y moderno. En: Oralidad. Para el Rescate de la Tradición Oral de América Latina y el Caribe. Anuario 14. Las raíces indígenas. La Habana: UNESCO.

León Portilla, M. (1982). Rostros del México antiguo. Veinte textos. Revista de la Universidad de México, 38 (14), 25-35.

León Portilla, M. (1983). Cuícatl y Tlahtolli las formas de expresión en náhuatl. Estudios de cultura náhuatl, (16). México D.F.: Universidad Autónoma de México.

León Portilla, M. (1984). Literatura de Mesoamérica. México: Secretaría de Educación Pública. 
León Portilla, M. (2008). La tinta negra y roja: antología de poesía náhuatl. Barcelona: Círculo de lectores: Ediciones ERA: Galaxia Gutenberg.

Martínez, J.L. (1998). Semblanza de Nezahualcóyotl. México: Fondo de Cultura Económica.

Nezahualcóyotl, A. (1992). Poetas de España y América. Colección de poesía Quinto centenario. (Antología 1). Bogotá: Editorial Tiempo Presente.

Osuna Ruiz, R. (1968). Introducción a la lírica prehispánica. Maracaibo: Universidad del Zulia, Facultad de Humanidades y Educación.

Todorov, T. (2005). La conquista de América. El problema del otro. México. Siglo XXI Editores. 